\title{
Emergency Room Nurses' Views on Bedside Shift Reporting
}

\author{
Crystal L. Foster ${ }^{1}$, Samuel P. Abraham ${ }^{1} \&$ Deborah R. Gillum ${ }^{1}$ \\ ${ }^{1}$ Bethel University School of Nursing, Mishawaka, Indiana, USA \\ Correspondence: Samuel P. Abraham, Associate Professor of Nursing, Bethel University, 1001 Bethel Circle, \\ Mishawaka, Indiana, USA.
}

Received: November 17, 2019

Accepted: November 28, 2019

Online Published: December 5, 2019

doi:10.20849/ijsn.v4i4.677

URL: https://doi.org/10.20849/ijsn.v4i4.677

\begin{abstract}
Bedside shift reporting is a form of communication used by nurses to communicate with each other regarding the patient plan of care. Although bedside shift reporting is required by The Joint Commission and is a required hospital policy, there are inconsistencies in the emergency room nurses performing the task. The purpose of this study was to describe emergency room nurses' views on bedside shift reporting. A qualitative research study was conducted using a semi-structured interview process. Colaizzi's data collection and analysis strategy were used to determine emerging themes. Peplau's interpersonal relations and Benner's novice to expert theories were used to help guide this study. Fifteen emergency room nurses were interviewed, and seven themes emerged from the data collected. Three themes, nurse accountability, nurse introduction, and patient involvement were identified as benefits of bedside shift reporting. Four themes, bedside shift report not done, emergency room situations, emergency room environment, and time factors were identified as challenges of bedside shift reporting. The study helped to determine the need for additional educational opportunities for the emergency room nurses, emergency department, and the organization to increase the consistency of the reporting process.
\end{abstract}

Keywords: bedside reporting, patient handoffs, nurse to nurse shift reports, nursing shift reports

\section{Introduction}

Nursing shift report is a long-time practice of communication. Shift report among nurses has been defined as "a system of nurse-to-nurse communication between shift changes intended to transfer essential information for safe, holistic care of the patient" (Caruso, 2007, p. 17). Patient handoffs, or shift reports, usually occur during the change of shift between the off-going and on-coming nurses. The process for handoff communication between caregivers is recognized by The Joint Commission (TJC) as a required standard under the provision of care, treatment, and services (Olson-Sitki, Weitzel, \& Glisson, 2013). A gap exists between the recommendations and the actual practice regarding change of shift report at the patient's bedside. The purpose of this study was to describe emergency room (ER) nurses' views on bedside shift reporting (BSR). A qualitative research was the approach chosen for this study on bedside reporting.

\subsection{Background}

The sharing of patient information and transferring of patient care from one Registered Nurse (RN) to another is an essential component of communication within the healthcare system. With the complexity of patient healthcare needs and the multiple disciplines involved in patient treatment plans, the method in which this information is shared must be effective. Also called handoffs or handovers, this method of communication refers to the transfer of responsibility and accountability for patient care from one or more clinicians during their hospital stay (Jeffs et al., 2013). Patients trust those involved in the process are providing each other with the necessary information to achieve the best patient outcome.

The steps in shift report must be strategic and standard in practice to ensure the sharing of critical patient-care information. Effective communication between nurses during shift report is essential for patient safety and the assurance of the delivery of quality patient care. Although an effective form of communication, patient handoffs are also a potential source of communication error for hospitalized patients (Ford \& Heyman, 2017). The Institute of Medicine's 1999 report: To Err is Human: Building a Safer Health System, revealed that medical errors cause at least 98,000 unexpected deaths in U.S. hospitals each year, signifying the need to change the way healthcare is delivered (Burke \& McLaughlin, 2013). TJC estimated $80 \%$ of serious medical errors involve miscommunication between caregivers during the transfer of patient care (Mardis et al., 2016). Barry (2014) 
reported that more than $43 \%$ of malpractice claims were related to inaccurate or incomplete information passed during patient handoffs. Incomplete or miscommunicated information during these handoffs contribute to failures in the reporting process resulting in negative patient outcomes.

To obtain accurate, patient-focused information, organizations have adopted the practice of bedside reporting. The importance of an informative and effective nurse-to-nurse report was part of TJC National Patient Safety Goals (NPSGs) (Caruso, 2007). Shift change was also included in TJC's 2009 NPSGs, requiring shift handoffs to include current patient information about the care, treatment, current condition, and anticipated changes in the patient (Rush, 2012). According to the National Public Safety Foundation, bedside reporting improves and promotes both patient safety and the practice environment for nurses (Pearce \& McCarry, 2014). Bedside reporting is shown to be an effective means of communicating patient-care information, benefiting both patients and the nursing staff.

\subsection{Statement of the Problem}

Nurse-patient rapport is the basis for nursing practice in every organization. BSR is the precise time for the nurse, patient, and family to establish and build on a therapeutic relationship. Bedside shift reporting is an opportunity for nurses to allow patients, with their families, to actively participate in their own treatment plan. BSR is a face-to-face interaction that involves the patient, introduction of the on-coming nurse, clarification, and resolution of erroneous information, and immediate assessment of the patient (Mardis et al., 2016). There is growing evidence that nurse-to-nurse handoffs involving patients in the reporting interaction have positive outcomes for patients, nurses, clinical teams, and organizations (Jeffs et al., 2013).

A hospital in northern Indiana implemented a bedside reporting policy to support the improvement of patient care experiences. The shift reporting policy includes both nurses and patients with the intent to improve communication, foster patient-caregiver trust, and promote patient safety practices. The shift reporting process is conducted on in-patient care units and the ER department. Although the in-patient unit and ER nurses deliver care for patients who present with different acuity levels, the way patients enter each unit is vastly different. The ER environment is fast-paced, disorganized, and unpredictable, while in-patient units are busy, the environment is more structured, and organized. ER nurses plan of care and schedule of events may depend on how and what type of patient enters their doors. The type of uncertainty may influence the consistency and impact the delivery of the BSR experience. It is hoped that interviewing ER nurses regarding bedside reporting will provide answers to the results of implementing this policy.

\subsection{Purpose of the Study}

The purpose of this study was to describe ER nurses' views on BSR. This research study presented nurses with the opportunity to voice their opinions regarding bedside shift reporting. Using open-ended questions, the researcher identified common themes related to exploring how ER nurses view the shift reporting process. Considering nurses' viewpoints allows organizational leaders the opportunity to initiate conversations with staff, potentially leading to solutions to address any problems related to bedside reporting while continuing to implement effective steps of the process.

\subsection{Research Question}

What are emergency room nurses' views on bedside shift reporting?

Guiding interview question: What are your views on bedside shift reporting? Prompts include:

- What training did you receive regarding bedside shift reporting?

- What are the benefits of bedside shift reporting?

- What are your concerns with bedside shift reporting?

- What would you change in the bedside shift reporting process?

- Describe a time when bedside shift reporting worked well and improved patient care.

- Describe a time when bedside shift reporting did not work out well.

- How does management encourage bedside shift reporting?

- What else would you like to tell me about bedside shift reporting?

\section{Literature Review}

The literature review on bedside reporting was completed using English language articles published between 2000 and 2018. A few landmark articles and theory books were published before the year 2000 are included. The 
EBSCOhost, Cumulative Index to Nursing and Allied Health Literature (CINAHL), Journals@ Ovid, and Google search were used to retrieve relevant published articles. Articles included in the literature review focused especially on bedside reporting and those that compared previous shift report methods to BSR. Keywords used were bedside reporting, shift reports, handoffs, patient handoffs, nurse to nurse shift reports and nursing shift reports.

\subsection{Empirical Literature Review}

\subsubsection{Benefits of Bedside Shift Reporting}

Research studies substantiate the benefits of bedside shift reporting and the importance of nurses supporting the implementation of this process. This reporting technique demonstrates a form of therapeutic communication designed to improve the nurse-patient relationship. Effectively sharing patient information simultaneously with the nurse and the patient promotes an environment consistent with the goal of nursing, which is to deliver safe and quality patient care. Studies show bedside reporting increases patient satisfaction, improves patient safety, and encourages patient involvement (Ford \& Heyman, 2017; Gregory, Tan, Tilrico, Edwardson \& Gamm, 2014; Jeffs et al., 2013; Radtke, 2013; Sand-Jecklin \& Sherman, 2014; Tidwell et al., 2011; Wakefield, Ragan, Brandt $\&$ Tregnago, 2012). Improved nurse-to-nurse teamwork, nurse accountability, and an increased report accuracy were identified as positive outcomes (Burke \& McLaughlin, 2013; Gregory et al., 2014; Jeffs et al., 2013; Olson-Sitki et al., 2013; Pearce \& McCarry, 2014; Rush, 2012; Sand-Jecklin \& Sherman, 2014; Wakefield et al., 2012).

\subsubsection{Patient Satisfaction}

Several studies showed patient satisfaction as one of the most reported benefits of bedside reporting (Gregory et al., 2014; Jeffs et al., 2013; Mardis et al., 2016; Olson-Sitki et al. 2013; Radtke, 2013; Rush, 2012; Sand-Jecklin \& Sherman, 2014; Small \& Fitzpatrick, 2017; Tidwell et al., 2011; Wakefield et al., 2012). Sand-Jecklin and Sherman noted one of the primary goals of nursing practice is the improvement in patient satisfaction. Active communication and sharing of information between nurses and patients in real-time are venues to improve patient satisfaction (Radtke, 2013).

Radtke's (2013) study revealed that BSR improved patient satisfaction scores. Patient surveys taken after hospital discharge indicated that patients were satisfied during their stay; however, nursing communication during the patient's stay could be improved. In the study, Lewin's planned changed theory was used to move the unit from taped nurse-to-nurse shift report to the bedside shift report. After the implementation of bedside reporting, they monitored patient satisfaction using external data gathered by Professional Research Consultants. At three months, there was a rise in the satisfaction of nursing communication score to $87.6 \%$. This satisfaction score was an increase from the $75 \%$ reached in the previous six months. Although the goal of $90 \%$ was not reached, the study showed this change in practice had a positive impact (Radtke, 2013).

\subsubsection{Patient Safety}

Studies have indicated improved patient safety is a crucial benefit of BSR (Burke \& McLaughlin 2013; Caruso, 2007; Gregory et al., 2014; Hagman, Oman, Kleiner, Johnson, \& Nordhagen, 2013; Jeffs et al., 2013; Rush, 2012; Sand-Jecklin \& Sherman, 2014; Tidwell et al., 2011). In response to TJC's NPSGs, BSR has been supported as improving patient safety (Gregory et al., 2014). Sand-Jecklin and Sherman revealed a decline in patient falls at shift change after the implementation of bedside handoffs. Burke and McLaughlin confirmed an increase in patient safety, acknowledging bedside handoffs allow nurses the opportunity to intervene in an adverse patient situation that might have gone unnoticed until much later using previous reporting methods.

\subsubsection{Patient Involvement}

Previously, shift report occurred at the nurses' station or staff breakroom and rarely included the patient. Studies indicate increased patient involvement as another benefit of BSR (Caruso, 2007; Gregory et al., 2014; Jeffs et al., 2013; Mardis et al., 2016; Radtke, 2013; Rush, 2012; Sand-Jecklin \& Sherman 2014; Small \& Fitzpatrick, 2017; Tidwell et al., 2011; Timonen \& Sihvonen, 2000; Wakefield et al., 2012). The research revealed patients feel a greater sense of involvement and improved satisfaction when a report is given at the bedside versus an area away from the patients (Grimshaw, Hatch, Willard, \& Abraham, 2016). Bedside reporting addresses TJC's NPSG \#13, a safety strategy that encourages the patient's active involvement in their care (Rush, 2012). Ford and Heyman (2017) noted this method offered patients an opportunity to understand their plan of care better. Because of the importance of obtaining accurate, patient-focused information, organizational leaders have implemented policies to support the practice of involving patients in bedside reporting. 


\subsubsection{Nursing Teamwork}

Multiple healthcare auxiliary members contribute to the overall patient treatment care plan, yet nurses are central to reaching positive patient outcomes. Because of their essential roles, nurses must have effective communication skills and model the behaviors of professionalism and mutual respect, especially in the presence of patients and families. Policies requiring nurses to perform shift report at the bedside encourages nursing teamwork (Burke \& McLaughlin, 2013; Olson-Sitki et al., 2013; Pearce \& McCarry, 2014; Rush, 2012; Sand-Jecklin \& Sherman, 2014; Wakefield et al., 2012). Nurses demonstrating teamwork assures patients the healthcare team supports the plan of care.

\subsubsection{Nurse Accountability}

Nurses practice with a knowledge and skill level to deliver quality patient care. Nurses acknowledge that their decisions and actions, directly and indirectly, affect patient care. Nurses are accountable to themselves, the team, the profession, and the organization. Bedside reporting supports accountability between shifts (Hagman et al., 2013; Jeffs et al., 2013; Olson-Sitki et al., 2013; Rush, 2012; Sand-Jecklin \& Sherman, 2014; Wakefield et a., 2012). Accountability is obtaining maximum information from the off-going nurse and the team, which includes visualizing patients, asking questions, and obtaining data to prioritize and manage the patient load effectively (Jeffs et al., 2013).

\subsubsection{Report Accuracy}

The importance of an informative and effective nurse-to-nurse report is part of TJC NPSGs (Caruso, 2007). "Nurse shift reports and nurse handovers are two of the most critical processes in patient care that can support patient safety and reduce medical errors in the United States" (Gregory et al., 2014, p. 541). It is important to obtain and transfer accurate patient information for continuity of care. Inaccurate or insufficient reporting has the potential to cause permanent disabilities or even death to patients. Involving nurses and staff in this communication process decreases avoidable risks. The increase in nurses' daily responsibilities confirms the importance of a standardized reporting process to lessen those risks.

Jeffs et al. (2013) completed a qualitative study in an inner-city, acute care teaching hospital to explore nurses' experiences and perceptions associated with the implementation of bedside nurse-to-nurse shift handoff reporting. Previous reporting methods included taped, verbal, or written reports. A total of 43 female interviews were gathered from a variety of clinical cohorts. The average years of working as a nurse were 15.2 years (range 0.5-41 years). These interviews occurred 18 months following the initial implementation and six months after the relaunch of bedside reporting. In conclusion, the participants described how BSR provided an opportunity to check and clarify information, which allowed the nurse and patients to identify, intercept, and correct potential and actual errors in care (Jeffs et al., 2013).

\subsubsection{Challenges to Bedside Shift Reporting}

Research reveals there are challenges associated with bedside shift reporting. These challenges affect both nurse-to-nurse and nurse-to-patient relationships. In certain practice care settings and patient situations, implementing this reporting method presents difficulties, including lack of privacy, use of medical jargon, which is difficult for the patients to understand, lack of time, and lack of skill for the nurses. Recognizing these barriers should prompt organizational leaders to create and implement continuing education and support.

\subsubsection{Privacy}

Nurses and patients express concerns with maintaining confidentiality and the potential of breaching Health Insurance Portability and Accountability Act (HIPAA) while conducting BSR (Burke \& McLaughlin, 2013; Dorvil, 2018; Grimshaw et al., 2016; Timonen \& Sihvonen, 2000; Scheidenhelm \& Reitz, 2017; Small \& Fitzpatrick, 2017; Williams, 2018). Burke and McLaughlin indicated that there is the potential to violate HIPAA because some nursing units still have semiprivate rooms. Dorvil also indicated nurses are afraid to violate patient privacy and to unintentionally disclose medical information unknown to the patient. These concerns lead to reluctance in staff to fully embrace the bedside reporting process.

\subsubsection{Use of Medical Jargon}

Involving patients in the BSR process is essential and required, yet it is hindered when they do not understand the shared information. Studies have shown patients indicate another barrier to the reporting process is the use of medical jargon by the nursing staff (Dorvil, 2018; Sand-Jecklin \& Sherman, 2014; Scheidenhelm \& Reitz, 2017; Timonen \& Sihvonen, 2000). Medical jargon could confuse patients while causing or increasing anxiety regarding their hospital experience (Scheidenhelm \& Reitz, 2017). The use of too much professional language 
has been proposed as the reason communication barriers exist between medical staff and patients (Timonen \& Sihvonen, 2000). Consistency and awareness of staff are ways to address these concerns.

\subsubsection{Time Factor}

BSR must be systematic in its delivery for the process to be effective. Nurses expressed fear that the bedside report would take longer because of interruptions and more involvement from the patient and family (Burke \& McLaughlin, 2013; Dorvil, 2018; Grimshaw et al., 2016; Scheidenhelm \& Reitz, 2017; Williams, 2018). With the off-going shift usually ready to turn over care, facing additional time on the clock may cause some hesitancy to complete report effectively or even conduct report at the bedside.

\subsubsection{Lack of Skill}

The BSR process is designed to share and review certain patient information in a methodical approach. Nurses are faced with the responsibility of understanding what information is necessary to share and ensure the delivery is appropriate. Research has indicated the lack of skill to communicate effectively essential patient care information is another challenge to bedside shift reporting (Burke \& McLaughlin, 2013; Cairns, Hoffmann, Dudjak \& Lorenz, 2013; Dorvil, 2018; Small \& Fitzpatrick, 2017; Williams, 2018). Cairns et al. stated, "an experienced nurse may provide more in-depth information or may conversely assume a baseline of knowledge among peers that may not be present" (p. 160).

Studies indicated some nurses might not have the awareness of, and the skills required to, engage in a patient-centered approach to care, feel comfortable talking in front of patients and are intimidated with potential questions posed by patients and their families (Dorvil, 2018). Small and Fitzpatrick (2017) noted a lack of training in communication and delivery of the patient information. The stress caused by the process may result in staff avoiding BSR completely when reasonable excuses present, such as the patient is sleeping (Small \& Fitzpatrick, 2017). Organizational leaders must recognize a lack of communication skills as a risk for adverse patient outcomes and create work environments that support the consistency of this practice.

\subsection{Theoretical Literature Review}

The framework for this research study was adapted from Peplau's "interpersonal relations" theory and Benner's "from novice to expert" theory (Benner, 1982; Peplau, 1952). Nursing is more than tasks; it's a profession of expertise, with skills to meet the needs of patients (Radtke, 2013). Peplau's theory defined the relationship between the nurse and the patient as therapeutic, based on trust and mutual understanding with open communication that fosters mutual goal setting (Radtke, 2013).

Effective BSR requires competent shift reporting skills, with the information communicated between nurses, patients, and families being shared strategically. There must be a consistent demonstration of the correct reporting process to ensure nurses become efficient. Relating the novice to expert theory, bedside shift reporting allows junior level nurses to benefit from the senior nurse's procedural and experiential knowledge, giving less-experienced nurses more exposure to other nurses' techniques and approaches to patients (Grimshaw et al., 2016). A further theoretical literature review is found in the conceptual framework section.

\subsection{Summary of the Literature Review}

A review of the literature identified both the benefits and challenges associated with BSR from both a nursing and patient perspective. Although others are mentioned, there were three common categories related to the benefits of bedside reporting for the patient. The studies revealed BSR increases patient satisfaction, improves patient safety, and encourages patient involvement. For nurses, the studies revealed BSR promotes nurse-to-nurse teamwork, nurse accountability, and increased report accuracy. As healthcare organizations establish goals of achieving positive patient outcomes, the benefits of the process should solicit consistent implementation of this shift reporting process.

Research has shown a standardized approach to bedside reporting. Supportive attitude by the managers toward nurses can enhance shift handoffs and lead to positive outcomes for both nurses and patients (Scheidenhelm \& Reitz, 2017). The movement towards implementing BSR as part of the standard of care contributes to the overall effectiveness for all within the healthcare system. Hospital Consumer Assessment of Healthcare Providers and Services (HCAHPS) reported improvement in scores and patient surveys after bedside handoff was implemented in practice care settings (Ford \& Heyman, 2017; Radtke, 2013; Sand-Jecklin \& Sherman, 2014). When compared to previous methods of shift reporting, BSR is shown to improve communication between the on-coming and off-going nurses, patients, and families. 
While studies maintain there are benefits of BSR, they also reveal the challenges associated with the reporting process. The lack of privacy and potential breach of HIPAA are concerns for both patients and nurses. Nurses express concerns with the length of time it takes to complete shift report at the bedside, and others identify the lack of communication skills to report effectively information as a barrier. Patients view the inability to understand the information reported as a barrier to participating in the process. Gregory et al. (2014) also suggested despite strong evidence demonstrating the benefits of BSR; issues remain regarding the sustainability of the process after implementation. A few studies reported the longitudinal results of BSR as inconsistent (Gregory et al., 2014). Burke and McLaughlin (2013) recommended after the BSR process is implemented, agencies need to include a systematic approach to providing ongoing feedback. Jeffs et al. (2013) explained that the research focus has been on describing handoff practices, the need for change, and strategies used to implement the change, with less known about how nurses experience and perceive their participation in the process.

A gap in published nursing research on the topic of BSR was found after a thorough review of the literature. There seem to be pros and cons of BSR. Exploring the views on BSR may help patient and nurse satisfaction and add to the current literature. Research conducted from a nurses' perspective may provide the necessary insight to increase the process compliance long-term.

\section{Conceptual Framework}

\subsection{Peplau's Interpersonal Relationship Theory}

The nurse and patient relationship begin when the patient becomes a part of the healthcare system. The relationship is built from trust, respect, and a mutual commitment towards the plan of care. This joint effort includes identifying problems; understanding the problems and their variations in patterns; and appreciating, applying, and testing remedial measures to reach beneficial outcomes for the patient (Peplau, 1992).

Peplau defined nursing as an interpersonal, therapeutic process that takes place when professionals, such as nurses, engage in therapeutic relationships with people in need of health services (Peplau, 1992). The nurse-patient relationship is an essential component of nursing practice. To achieve positive patient outcomes, the nurse-patient relationship encounters four phases derived from the interpersonal relationship theory: orientation, identification, exploitation, and resolution. Orientation is the introduction, identification is defining roles, exploitation is acceptance, and resolution is discharge after the success of the other phases.

Peplau's theory is appropriate for this research study because it shows the influence of blending the nurse and patient relationship. During the bedside report, nurses introduce the on-coming shift nurse, identify patient needs, and discuss the plan of care with the patient, which leads to an improved trusting relationship (Scheidenhelm \& Reitz, 2017). This theory is reflective of the BSR process as it demonstrates the necessity of including both the nurse and patient in the process of working to achieve the desired patient outcome. Bedside shift reporting requires a purposeful routine of communication and interaction between nurses and patients. During the process, there is an overlap in the exchange of information with both nurse and patients providing information to gain an understanding of the plan of care.

\subsection{Benner's Novice to Expert Theory}

Benner's novice to expert theory suggests novice nurses start with an educational foundation and develop skills to provide quality patient care with repeat opportunities to perform the skill. The theory further suggests the nurse cannot practice beyond experience or be responsible for what they have not yet encountered (Benner, 2001). The theory further explains when nurses are engaged and exposed to different patient care experiences, there is learning that allows them to develop the skill to progress through levels of proficiency: novice, advanced beginner, competent, proficient, and expert (Benner, 1992).

Benner's from novice to expert theory was used by the researcher to address the problem by identifying factors that may influence the strategic practice of change-of-shift report at the bedside. Effective communication among nurses and patients contribute to improved nurse-to-nurse relationships and nurse-to-patient care experiences. The consistency of the BSR process helps novice nurses develop reporting skills that transition them to expert level. Nurses also gain knowledge and improve this shift reporting skill when participating with nurses who have a higher level of experience. 


\section{Definitions}

\subsection{Conceptual Definitions}

Peplau's (1952) interpersonal relations in nursing theory includes four phases of the nurse-patient relationship: orientation, identification, exploitation, and resolution. These reflect the relationship between the nurses and patients during BSR. Like bedside reporting demonstrates an exchange of information, the four phases overlap when used to describe the nurse-patient relationship. The orientation phase is the patient's impression that a problem has presented and requires them to seek assistance; included is how the nurse feels about providing help. The patient's understanding of how the interaction can help the outcome and responds selectively to the person offering the help is the identification phase. During the exploitation phase, rapport is established, and the patient accepts the nursing services offered. Resolution, the last phase, is met when the patient's physical and mental concerns are addressed and in their understanding of the care, they move towards a freeing process; demonstrating actions from dependency (Peplau, 1952).

Benner's (1982) novice to expert theory includes five levels of proficiency. Clinicians are expected to move through novice, advanced beginner, competent, proficient, and expert levels, which can demonstrate the path that consistent and efficient BSR takes in achieving positive patient-care outcomes. Novices are beginners who have no experience with the situations in which they are expected to perform tasks. The advance beginner is one who can demonstrate marginally acceptable performance. Competency, typified by a nurse who has been on the job for up to three years, develops when the nurse begins to see his or her actions in terms of long-range goals and plans. The proficient performer perceives actions as wholes, rather than in terms or aspects, and performances are guided by maxims. At the expert level, the performer no longer relies on an analytical principle to connect his or her understanding of the situation to an appropriate situation (Brenner, 1982).

\subsection{Operational Definitions}

Variables explored in research must be defined prior to implementing a research study. Bedside, which referred to the patient's actual bedside, and does not include the doorway or the hall near the patient's room. Handoff was the transfer and acceptance of patient care responsibilities through effective communication at the change of shift achieved. Change of shift was the point where one nurse is completing their shift, and the next nurse is starting their shift. The off-going nurse was the caregiver transmitting the patient information and releasing the care of the patient to the next clinician. On-coming nurse was the caregiver who accepted the information and care of the patient. Shift included day, evening, and night shift. It also included the 8-hour and 12-hour shifts. Report was similar to handoff communication and detailed pertinent information about the patient. Emergency room was the department of a hospital that provides immediate treatment for acute illnesses and trauma.

\section{Methodology}

A qualitative design with a semi-structured interview process was used to conduct this study. This process allowed the participants the opportunity to respond freely. A group of 15 ER nurses were interviewed in the midwestern United States.

\subsection{Data Collection and Analysis}

Face-to-face interviews were conducted using a prepared interview guide. Participants were encouraged to talk freely and to tell stories using their own words. Each interview lasted from 15 minutes 45 minutes. At the end of each interview, the participants were reminded about the need for a second contact face-to-face or via telephone to discuss the study findings and to make sure that the study findings reflected their own experiences. Attainment of data saturation was determined by the main researcher and by the professor in a process carried out in parallel with data collection. The transcripts were double-checked for accuracy.

The following steps represent Colaizzi process for phenomenological data analysis (Speziale \& Carpenter, 2007):

- Each transcript was read and re-read to obtain a general sense about the whole content.

- For each transcript, significant statements that pertained to the phenomenon under study was extracted. These statements were recorded on a separate sheet noting their pages and numbers.

- Meanings were formulated from these significant statements.

- The formulated meanings were sorted into categories, clusters of themes, and themes.

- The findings of the study were integrated into an exhaustive description of the phenomenon.

- The fundamental structure of the phenomenon was described. 
- Finally, validation of the findings was sought from the research participants to compare

The researcher's descriptive results with their experiences.

\subsection{Sampling}

The sample was 15 ER nurses with varied years of ER experience. The sample was one of convenience as the nurses were known to the researcher. Snowball sampling was used to obtain further participants as needed. Inclusion criteria for the study included those performing direct patient care as an RN in the ER. The participants were registered nurses older than 18 years of age who participated in the bedside reporting process. As most of the nurses were known to the researcher, it was convenient to locate and arrange the interview. Those nurses interested in participating in the study requested to schedule a convenient meeting time away from their employer and not during their working shift. Written informed consent was obtained prior to the interviews.

\subsection{Setting}

The interviews occurred in a quiet place away from the hospital. Selecting a location outside the hospital offered the participants the opportunity to freely express their opinions and experiences. The place offered privacy and was free of distractions and interruptions. The interviews occurred in locations based on the convenience of the participants.

\subsection{Ethical Considerations}

Before conducting the research study, the researcher obtained permission from the college Institutional Review Board. Participants read and signed informed consent prior to participating. Their identities were not disclosed at any time during the research process. The researcher ensured the confidentiality of each participant throughout the study. Each participant was assigned a number based on their order in the interview process. The interview was recorded with the participant's permission and transcribed verbatim. The recorded information was deleted after transcription. All transcribed information, consents, and interview documents are stored in locked cabinets by the researcher and will be destroyed after three years.

\subsection{Interview Guide}

Prior to the interview; the participants completed a 5-item demographic form, identifying the years of RN and ER experience, level of education, and current practice with the BSR process. The demographics are important to show an association with the background of the participant and their responses. The level of education is important to determine whether the educational level influenced the research response. Also, the nurses' BSR compliance status determined how they viewed the process. The interview results were transcribed into a Word document and themes were analysed. The researcher contacted each participant for a follow-up meeting to confirm understanding of the responses. The follow-up meeting offered participants the opportunity to provide additional information they did not think of during the initial interview.

\section{Results}

\subsection{Demographics}

The descriptive statistics were used to show the break down by gender, years of experience, education, and frequency of completing BSR (see Table 1). Male and female nurses were solicited to participate, but $100 \%$ who responded were female. Fifty-three percent of the nurses had 6-10 years of experience as an RN. Six to 10 years was the length of ER experience for $47 \%$ of the participants. A BSN was the highest degree completed for 13 out of 15 or $87 \%$ of the nurses. Fifty-three percent of the nurses reported they completed BSR sometimes.

Table 1. Descriptive statistics for ER nurses demographics

\begin{tabular}{lll}
\hline Variable & $\mathrm{f}$ & $\%$ \\
\hline Gender & & $0 \%$ \\
\hline Male & 0 & $100 \%$ \\
\hline Female & 15 & \\
\hline How many years have you been a RN? & & $13 \%$ \\
\hline $0-5$ & 2 & $53 \%$ \\
\hline $6-10$ & 8 & $13 \%$ \\
\hline $11-15$ & 2 & $20 \%$ \\
\hline $16+$ & 3 & \\
\hline Highest Level of Education & & $13 \%$ \\
\hline ADN & 2 & \\
\hline
\end{tabular}




\begin{tabular}{lll}
\hline BSN & 13 & $87 \%$ \\
\hline How long have you worked as an ER nurse? & & $33 \%$ \\
\hline $0-5$ & 5 & $47 \%$ \\
\hline $6-10$ & 7 & $20 \%$ \\
\hline $11-15$ & 3 & \\
\hline How often do you complete BSR? & & $33 \%$ \\
\hline Often & 5 & $53 \%$ \\
\hline Sometimes & 8 & $13 \%$ \\
\hline Rarely & 2 & \\
\hline
\end{tabular}

Note. $(\mathrm{N}=15)$.

\subsection{Emerging Themes}

Using open-ended questions, common themes were identified based on the participant's response to the research question and the prompts. From the responses, the themes were categorized based on individual words, or phrases, or meaning of the words or phrases. Those themes were grouped as either a benefit or a challenge related to BSR. Three benefits and four challenges were identified related to the implementation of BSR.

Two major themes emerged from the interviews. Theme one was "Challenge of BSR" with 214 mentions. Theme two was "Benefits of BSR" with 110 mentions. The sub-themes from each major theme were ranked from the most frequently used to the least frequently used. The sub-themes identified as challenges of BSR included (1) ER situations, (2) BSR not done, (3) ER environment, and (4) time factor. Sub-themes identified as benefits of BSR included (1) nurse accountability, (2) nurse introduction, and (3) patient involvement. The themes and sub-themes are illustrated in Figure 1. The research participants are identified as P1 through P15.

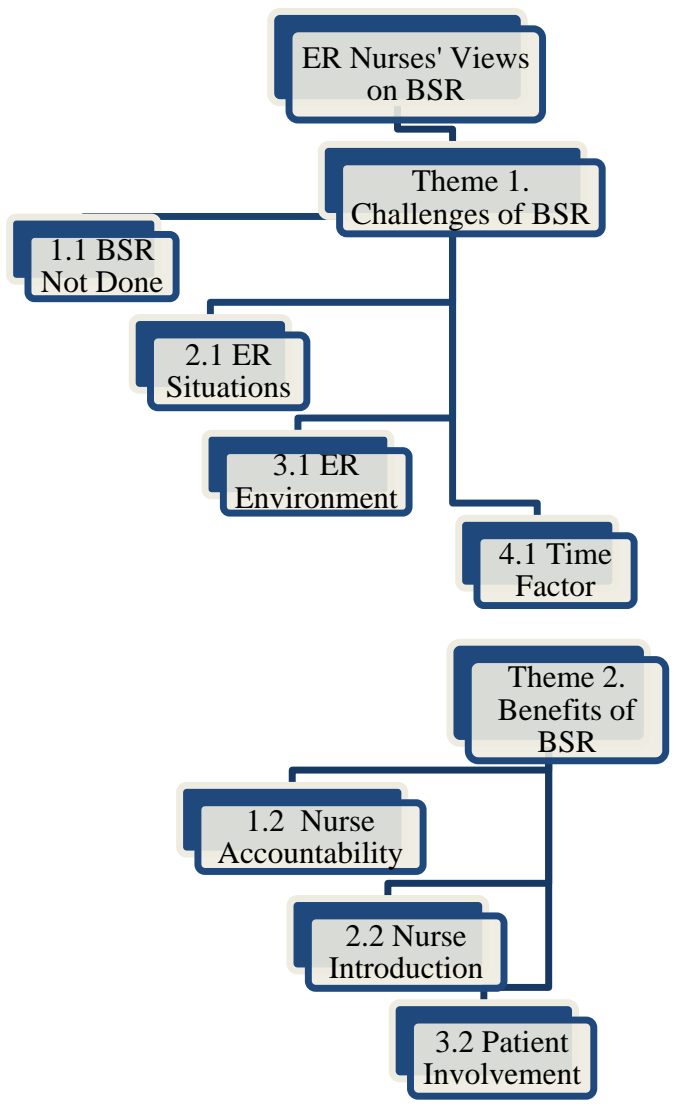

Figure 1. Ranked themes and sub-themes for ER nurses' views on BSR 


\subsubsection{Challenges of BSR}

\subsubsection{BSR Not Done}

All 15 nurse participants voiced concerns associated with the reasons BSR were not performed by ER nurses. From the participants' responses, nurses' attitude, nurse resistance, inconsistency, and experienced nurse resistance explained reasons why BSR was not done in the ER. Nine of the participants discussed frustration about the need to change the ER culture regarding BSR. Many participants viewed BSR as optional instead of the expectation of the department. Although emphasized and encouraged, P5 reported nurses just do not do it. P2 was frustrated by the lack of momentum from the on-coming shift's readiness to conduct BSR. She reported nurses stopped to make coffee or eat breakfast once they arrived on the unit, which added additional time to the off-going nurses' shift. She believed the BSR process would go smoother and require less time if staff presented with a ready to work attitude. P3, P11, P12, and P13 expressed concerns regarding ER nurses after a long and busy 12-hour shift, feeling burnt out and too tired and not motivated to provide BSR. By the end of most shifts, nurses are hurried and ready to go home.

All 15 participants agreed BSR is important, beneficial, and holds value on some level, but reflected on the difficulties due to nurses resisting the process. P9 stated, it is a good practice in theory, but there is great resistance compared to what the organization and management expect. $\mathrm{P} 2$ noted, BSR is not well received by all the ER staff. P4 reported that there were pros and cons with the reporting process but admitted she too lacked the consistency in performing the process. P11 generally liked BSR, but not everyone she worked with did. She encouraged bedside reporting but stated, I refuse to spend the time arguing to convince a nurse to complete it. P1, P6, P8, P10, and P14 reported BSR was circular, starting as high priority usually after an incident or negative occurrence and then later went away again. P14 stated, it feels like a fad, pushed for like everything else.

Some of the participants identified the greatest resistance of BSR came from the experienced ER nurses. P4 reiterated, experienced nurses resist the most, informing others they can figure it out on their own. P14 reported, the ER culture needs changing; newer nurses feel experienced nurses are intimating, so they don't even ask them to perform bedside report. P15 believed the culture should change with the experienced ER nurses first. If the experienced nurses resist BSR, orientees and new nurses will not ask. ER is a tough culture for a new grad to break into. New nurses want to be liked and are not forceful enough to insist on a nurse with 10 to 15-year experience to conduct BSR. Receiving push back could make for a rough experience for a new nurse. P15 stated she wanted management to do more to get experienced nurses on board.

\subsubsection{ER Situations}

Depending on zone assignments, ER nurses are always prepared to care for the wide range of patients that may present through the ER doors. The participants described situations specific to the ER that impacted their ability to do BSR. These ER situations, which included situational behaviors and patient acuity, were identified as barriers to accomplishing BSR consistently in the ER. P2 stated, hearing the words BSR makes me cringe not because the process is a bad idea, but the required practice is not appropriate for every ER patient.

Upset patient and family members, psychiatric and combative patients, and 'frequent flyers' are the patient populations that the participants identified who typically create barriers to completing BSR. Patients and their family members, although understandable, get upset due to long ER wait times. Patients wait in the waiting areas and still may have to endure additional wait time once assigned to an examination room. P3 described a time she brought another nurse to the bedside for report instead of the doctor. The situation turned into an opportunity where the family attacked the new nurse. BSR was not perceived as appropriate at that time. P5, P10, P13, and P15 shared similar feelings when describing difficult, demanding, and entitled patients and family members as barriers to completing BSR.

Due to the sensitive information and behavioral concerns associated with psychiatric and combative patients, shift report was conducted outside the room. Conducting a bedside report may escalate the circumstance or create an unsafe environment for the nurses. P7 stated, once patients are calmed in those situations, BSR is not appropriate or wise as the patient may feel defensive, get worked up again, or cause both nurses to feel unsafe. $\mathrm{P} 9$ shared similar experiences when caring for agitated or mentally challenged patients who were screaming, yelling, or restrained.

Three nurse participants discussed the presentation of 'frequent flyers' in the ER. A 'frequent flyer' is a label given to patients with multiple ER visits for the same complaint in a short period of time. P5 and P10 admitted the unwillingness of many nurses to perform BSR on that specific patient population because they are usually 
here with similar and previously substantiated false complaints. P9 stated she does not like to go into the room of repeat offenders because nurses already know who they are and why they are there.

With the ER triage system, participants believed BSR should be performed based on patient acuity. Many ER nurses agreed BSR is appropriate and necessary for higher acuity patients, yet a waste of time for lower acuity patients. Critical, trauma, and complex patients are higher acuity, and vaginal pain or toothaches are lower acuity. P1 stated on critical patients, she conducted BSR room-to-room, but with lower acuity patients typically placed in the rapid treatment area (RTA), she did not. Those patients usually received one intervention and were discharged home. P2, P5, and P12 reported that they insisted on BSR with critical or trauma patients with multiple intravenous (IV) lines, titrating drips, and acute neuro changes. Yet, P7 stated she will not do BSR on lower acuity patients presenting with tooth pain or medication refills. She described it as a waste of everybody's time. P14 agreed on BSR for critical patients, but not for a lower acuity patient presenting with ankle pain. A patient presenting with a simple hand fracture, P6 quoted how she'd give the simple report at the desk, gave Norco, order to splint hand then will be discharged home.

\subsubsection{ER Environment}

The ER is a challenging environment to consistently conduct BSR when many unpredictable circumstances could occur at a moment's notice. With the ER being a task-based environment, P13 noted it is a difficult setting to conduct BSR consistently. P5 and P7 described ER as fast-paced and vastly different than inpatient units. P10 knew that the inpatient units delay receiving new patients during shift change. Unfortunately, the ER staff does not have sympathy for the units, because the ER does not get that option. P10 described the ER as a go-go environment. P3 and P14 discussed the possibility of any nurse getting two ambulances at shift change or pulled to assist in a trauma, making it impossible to conduct BSR. Both the off-going and on-coming nurses would possibly have to assist.

Nurse participants expressed concerns regarding the lack of training on how to apply the BSR process in an ER setting. Ten participants denied any formal training from management regarding the implementation of the reporting process in an ER setting. P5 stressed the expectation of performing bedside reporting, but stated, received no specifics on how it is done. The training from orientation or in nursing school was not felt as applicable. P3 noted, a form or template would make bedside reporting easier and more organized. P11 stated, most of the ER does their own adjusted form of BSR, giving a version of the report outside the room.

\subsubsection{Time Factor}

Utilization of time is crucial to managing patient care and all the activities associated with the flow of ER. Many participants verbalized time is a major factor. Time was of the essence in the ER, so depending on patient situations, BSR was not conducted on every patient. P7 stated, BSR is reserved for critical patients. P1 stated, taking a full 30 minutes to give report puts the on-coming nurse 30 minutes behind starting the shift and completing patient tasks. With the potential for patient interruptions, nurses think BSR takes longer, noted P15. Nurses consider acuity when performing shift report, so when calculating the possibility of giving BSR on four patients takes more time than is necessary, according to P12.

\subsubsection{Benefits of BSR}

\subsubsection{Nurse Accountability}

Nurse accountability or 'being on the same page' were grouped together as a theme and identified as a benefit of BSR. The participants indicated BSR provided an opportunity for the off-going nurse to end and the on-coming nurse to begin patient care on the 'same page'. $\mathrm{P} 1$ stated, nurse accountability indicates both nurses agree with what is clinically going on with the patient at the time. Many participants reported nurse accountability was when they affirmed their patient's neurological status to monitor for changes, confirmed placement of IV reseals, verified IV fluids, medications, and infusion rates, and checked arterial lines and assessed wounds during BSR. P8 said it is better for the on-coming nurse to see what the off-going nurse describes when it comes to wounds, skins issues, or IV sites, as opposed to taking the nurse's word and assuming care blindly. P15 noted that nurse accountability or being on the 'same page' during BSR was when the off-going nurse leaves, ensuring the patient and everything is in good standing and nothing is left undone or while the on-coming nurse confirms patient status so not to walk into a train wreck.

Completing the report at the bedside, the nurses discussed the plan of care, any unfinished tasks, and pending test results. BSR was considered an opportune time for nurses to work together and accomplish essential patient care needs. P5 stated during BSR, nurses collaborate on whether something is missed and address it at that time. P13 also stated reporting at the bedside decrease communication errors... Instead of walking in a room and finding 
many things not done, the on-coming nurse addresses those issues at that moment before the off-going nurse leaves. Nurse accountability contributes to positive patient care outcomes, nursing teamwork, and effective communication.

\subsubsection{Nurse Introduction}

Introduction of the on-coming nurse to the patient was viewed by the participants as another benefit of BSR. A nurse-patient relationship begins once the patient is assigned to the nurse. After the nurse enters the room, the relationship is recognized and progresses from there. Many of the ER nurses interviewed viewed nurse introductions as a time for the off-going nurse to properly end and transfer care to the new nurse. P2 believed, dependant on the family and the time spent with them, some would feel jilted if she just left and a new nurse entered the room without a personal handoff. P6 noted, after providing care for hours, there is nothing worse for the patient than to have another nurse resume care without the previous nurse making the necessary introduction.

Most of the participants agreed nurse introduction was essential to build patient rapport and trust. Many patients and their families arrive to the ER scared and anxious. When the off-going nurse has provided quality care thus far, a proper transfer of care instills confidence in the patient and the new nurse moving forward. To build rapport, we owe it to our patients to be respectful and conduct some type of handoff process, noted by P13.

To establish a nurse-patient relationship was a main reason that participants gave for carrying out nurse introductions. The participants indicated that shift report in the ER still occurred often outside the patient room and most of the time, the nurse introduction was the only component of the reporting process occurring at the bedside. P6 indicated she likes to do a full report outside the room and the nurse introduction at the bedside. Because ER nurses care for varied patient caseloads in a short time frame, P6 usually started her shift report outside the room and continued at the bedside with only the nurse introduction. Unfortunately, P10, accounting for the varied patient population in the ER, believed BSR still occurred even if there was a brief presence at the bedside just to introduce the on-coming nurse to the patient. Lastly, P14 explained the practice of BSR, as a complete patient report usually done at the nurses' station followed by the nurse-to-patient introduction at the bedside. Agreeing nurse introduction is important for continuing patient care and building a rapport, nurse introduction alone is not performing BSR.

\subsubsection{Patient Involvement}

Yet another benefit of BSR includes involving the patients and their families in the plan of care to achieve quality patient care outcomes. Many of the research participants believed the practice of BSR supported continuity of patient care. Keeping patients and their families up-to-date and in the loop about care decisions was a benefit of BSR recognized by P9. She noted ER patients and families are often scared because they are uncertain and unaware, so for their best interest, the nurse taking time to provide information makes such a difference. P6 viewed BSR as an opportunity to close the communication loop between the nurse and the patient and their families.

\section{Analysis/Discussion}

The data collected with the semi-structured interviews were analyzed into emergent themes. Similar responses and phrases were grouped together. The themes were then ranked from greatest to least frequent. The research study successfully showed how ER nurses viewed BSR. The study revealed nurse accountability, nurse introduction, and patient involvement as benefits of the BSR process. The study also identified ER situations, BSR not done, ER environment, and time factor as challenges related to completing the BSR progress.

The study supports BSR as an effective communication method amongst nurses during the transfer of patient care in an ER setting. BSR increases patient involvement, boosts nursing accountability, and improves the effectiveness of communication among caregivers (Wakefield et al., 2012). The study also showed how participants believed not every ER situation is appropriate to conduct this method of reporting. Even in a fast-paced, unpredictable ER environment, BSR is still encouraged, but again not for every patient situation. With critical patients or those requiring monitoring for acute changes, the implementation of this reporting method benefits both the patient and the nurse. Nurses who implement BSR decrease the risk for errors or missed critical steps in patient care. BSR improves patient-care experiences. BSR contributes to improvements in safety and efficiency among nurses who have the chance to meet and briefly assess patients at the beginning of their shifts (Burke \& McLaughlin, 2013).

The research participants expressed concerns regarding staff resistance and inconsistency related to completing bedside reporting in ER. Time and lack of formal training were also identified as areas of concern. The research 
results indicated staff avoided BSR when there were issues, such as decreased communication, lack of training, and diminished comfort with the delivery of information in this format (Small \& Fitzpatrick, 2017). Research also supported that nurses resist BSR because they lack the skills to implement this reporting process (Dorvil, 2018). Sustainability of BSR should include ongoing nursing feedback, identification of barriers and facilitators to the new practice, modification of the reporting practice based on process evaluation techniques, encouragement through positive reinforcement, and continuous monitoring by peers and management (Dorvil, 2018).

\subsection{Peplau's Interpersonal Relationship Theory}

Once a patient register in the ER or emergently enters the ER, a nurse-patient relationship is established. After entering the room and engaging the patient, the BSR process begins. From the introduction, the nurse and patient exchange or overlap health information, moving towards a commitment to the treatment plan. The BSR process supports a therapeutic nurse-patient relationship. Peplau's interpersonal relationship theory begins with the nurse engaging in a relationship with the patient in need of health services (Peplau, 1992). The therapeutic relationship between the nurse and the patient is initially formed to meet a need but continues to develop from a place of trust and a mutual commitment to the plan of care. Peplau's (1952) interpersonal relations includes the overlap or exchange of four phrases of the nurse-patient relationship.

\subsection{Benner's Novice to Expert Theory}

Benner's novice to expert theory suggests novice nurses will transition to each level from repeat exposure to learning opportunities in the work environment and from an expert nurse sharing experiences. Unfortunately, the research participants identified challenges associated with new ER nurses and orientees attempting to transition from the novice to an expert level in the BSR process. The resistance to BSR comes from the experienced nurses who are entrusted to assist the new staff in developing this reporting skill. Ineffective nurse-to-nurse communication and inappropriate nurse-to-nurse behaviors were demonstrated when the participants revealed intimidation by the experienced nurses towards implementing BSR. Planning to follow Benner's novice to expert theory, this communication breakdown created an environment that hindered the transition of learning and interfered with the development of BSR skill.

\subsection{Limitations}

The sample size for this study was relatively small. The small convenience sample consisted of only 15 ER nurses known to the researcher. The sample was obtained from one region in Indiana. Each participant did not spend the full 45-60 minutes allotted for each interview due to their busy schedule.

\subsection{Implication for Nursing and Management}

BSR is an effective communication tool used to safely transfer patient care from nurse to nurse or nurse to the unit. The bedside reporting process is a policy and requirement of this healthcare organization. TJC also supports the implementation of BSR to improve patient-centered care and nurse communication (Gregory et al., 2014). This research study revealed ER nurses' views on BSR. From the study, participants identified nurse accountability, nurse introductions, and patient involvement as benefits of the BSR process, which is consistent with the literature. The research also showed how BSR helped to provide safe and quality patient-centered care. The ER nurses confirmed or corrected patient care or treatments during BSR, which also consistent with the literature. This study highlighted the inconsistencies of completing BSR in an ER setting. Unforeseen ER situations and ambulance arrivals were identified as reasons why the ER nurse may not achieve completion of the reporting process $100 \%$ of the time. These findings may cause management and the ER educator to review and adjust the BSR policy documenting possible exceptions. In addition, the research identified valid ER situations to support initiating patient report outside the room. These findings also may require management and the ER educator to review and make modifications or create a BSR policy which specifically addresses situations that are unique for the ER.

\subsection{Recommendations}

The recommendations resulting from this study are to re-educate the nurses of the importance of BSR as it relates to safe patient-centered care. BSR is an effective communication process beneficial to nursing and patients. Although the participants identified patient involvement as a benefit to BSR, the involvement of patients focused more on nursing providing updates instead of encouraging patient and family input. The participants viewed patient input and their questions during BSR as interruptions. Some participants failed to recognize that BSR is not just a nurse-to-nurse relationship, but the nurse-to-patient relationship at the bedside is an essential component of the process. Participants denied any formal training on how to implement BSR in an 
ER setting. The educational material and demonstrations used for teaching BSR are designed for inpatient settings which are vastly different from the ER. Management or educators may consider developing additional resources to demonstrate the process alignment with ER-specific situations.

Some of the research participants viewed BSR as optional instead of an expectation of the department. Many ER nurses were still performing shift report at the nurses' station and only conducting nurse introductions at the bedside. Although there were ER situations identified where this practice may be appropriate, the findings suggest the practice is occurring beyond those specific situations. These findings may require management, the educator, and the education committee to modify the BSR policy for the ER or reinforce when reporting outside the room is appropriate.

The participants identified communicational barriers that existed related to experienced ER nurses and their resistance to the implementation of BSR. The negative attitudes and behaviors have created a culture of intimidation directed toward orientees and new ER nurses towards BSR. Participants expressed frustration, possible fear of retaliation, and lack of support as a new staff if they reported their concerns. A suggestion is for management to increase presence during shift changes to observe the reporting process and demonstrate support to the nurses and the BSR process.

\section{Conclusion}

The research study successfully revealed ER nurses' views on BSR. Despite the benefits, there are issues concerning the implementation and sustainability of this nursing practice in the ER setting. In support of the literature, the study showed participants identified nurse accountability, nurse introduction, and patient involvement as benefits of the BSR. The study also revealed how participants confirmed patient care or addressed patient concern because of the implementation of BSR.

The study identified challenges specific to the ER, such as ambulance arrivals that influenced how consistent BSR was implemented in an ER setting. Because time is a crucial factor in the ER, the study showed the influence that patient acuity and ER-specific situations have on how ER nurses use their time and resources.

The study also identified barriers contributing to the ineffective communication between the experienced and new ER nurses as it relates to BSR. Identifying these barriers will hopefully assist management in the development of corrective strategies and educational opportunities for the nurses in the department. Because ER is a unique department, I believe there is a need for future related studies to further explore the implementation of this process in the fast-paced, high acuity, high turnover setting.

\section{References}

Barry, M. E. (2014). Hand-off communication: Assuring the transfer of accurate patient information. American Nurse Today, 9(1), 30-34. Retrieve from http://www.nursingworld.org/MainMenuCategories/ANAMarketplace/ANAPeriodicals/AmericanNurseTod ay/Archive/2014-ANT/Jan14-ANT/Issues-up-close-Jan14.pdf

Benner, P. (1982). From novice to expert. The American Journal of Nursing, 82(3), 402-407. Retrieved from http://www.jstor.org/stable/3462928

Benner, P. (2001). From novice to expert: Excellence and power in clinical nursing practice. Upper Saddle River, NJ: Prentice Hall Health

Burke, W., \& McLaughlin, D. (2013). Partnering for change. American Journal of Nursing, 113(2), 47-51. https://doi.org/10.1097/01.NAJ.0000426690.73460.d7

Cairns, L. L., Hoffman, R. L., Dudjak, L. A., \& Lorenz, H. L. (2013). Utilizing bedside shift report to improve the effectiveness of shift handoff. The Journal of Nursing Administration, 43(3), 160-165. https://doi.org/10.1097/NNA.0b013e318283dc02

Caruso, E. M. (2007). The evolution of nurse-to-nurse bedside report on a medical-surgical cardiology unit. Medsurg Nursing, 16(1), 17-22. Retrieved from https://www.ncbi.nlm.nih.gov/pubmed/17441625

Dorvil, B. (2018). The secrets to successful nurse bedside shift report implementation and sustainability. Nursing Management, 49(6), 20-25. https://doi.org/10.1097/01.NUMA.0000533770.12758.44

Ford, Y., \& Heyman, A. (2017). Patients' perception of bedside handoff: Further evidence to support a culture of always. Journal of Nursing Care Quality, 32(1), 15-24. https://doi.org/10.1097/NCQ.0000000000000201

Gregory, S., Tan, D., Tilrico, M., Edwardson, N., \& Gamm, L. (2014). Bedside shift reports: What does the evidence say? The Journal of Nursing Administration, 44(10), 541-545. https://doi.org/10.1097/NNA.0000000000000115 
Grimshaw, J., Hatch, D., Willard, M., \& Abraham, S. (2016). A qualitative study of the change-of-shift report at the patients' bedside. The Health Care Manager, 35(4), 294-304. https://doi.org/10.1097/HCM.0000000000000125

Grove, S., Burns, N., \& Gray, J. (2013). The practice of nursing research: Appraisal, synthesis, and generation of evidence (7th ed.). St. Louis, MO: Elsevier Saunders.

Hagman, J., Oman, K., Kleiner, C., Johnson, E., \& Nordhagen, J. (2013). Lessons learned from the implementation of a bedside handoff model. The Journal of Nursing Administration, 43(6), 315-317. https://doi.org/10.1097/NNA.0b013e3182942afb

Jeffs, L., Acott, A., Simpson, E., Campbell, H., Irwin, T., Lo, J., ... Cardoso, R. (2013). The value of bedside shift reporting; Enhancing nurse surveillance, accountability, and patient safety. Journal of Nursing Care Quality, 28(3), 226-232. https://doi.org/10.1097/NCQ.0b013e3182852f46

Mardis, T., Mardis, M., Davis, J., Justice, E., Holdinsky, S. R., Donnelly, J., .. Riesenberg, L. A. (2016). Beside shift-to-shift handoffs: A systematic review of the literature. Journal of Nursing Care Quality, 31(1), 54-60. https://doi.org/10.1097/NCQ.0000000000000142

Olson-Sitki, K., Weitzel, T., \& Glisson, D. (2013). Freezing the process: Implementing bedside report. Nursing Management, 44(7), 25-28. https://doi.org/10.1097/01.NUMA.0000431431.39008.af

Pearce, I., \& McCarry, N. (2014). Let's chat: Bedside reporting in the ed. Nursing, 44(8), 15-17. https://doi.org/10.1097/01.NURSE.0000451534.55587.4c

Peplau, H. E. (1952). Interpersonal relations in nursing: A conceptual frame of reference for psychodynamic nursing. New York, NY: G. P. Putnam's Sons.

Peplau, H. E. (1992). Interpersonal relations: A theoretical framework for application in nursing practices. Nursing Science Quarterly, 5(1), 13-18. https://doi.org/10.1177/089431849200500106

Radtke, K. (2013). Improving patient satisfaction with nursing communication using bedside shift report. Clinical Nurse Specialist, 27(1), 19-25. https://doi.org/10.1097/NUR.0b013e3182777011

Rush, S. (2012). Bedside reporting: Dynamic dialogue. Nursing Management, 43(1), 40-44. https://doi.org/10.1097/01.NUMA.0000409923.61966.ac

Sand-Jecklin, K., \& Sherman, J. (2014). A quantitative assessment of patient and nurse outcomes of bedside nursing report implementation. Journal of Clinical Nursing, 23, 2854-2863. https://doi.org/10.1111/jocn.12575

Scheidenhelm, S., \& Reitz, O. E. (2017). Hardwiring bedside shift report. The Journal of Nursing Administration, 47(3), 147-153. https://doi.org/10.1097/NNA.0000000000000457

Small, D. C., \& Fitzpatrick, J. J. (2017). Nurse perceptions of traditional and bedside shift report. Nurse Management, 48(2), 45-49. https://doi.org/10.1097/01.NUMA.0000511921.67645.47

Speziale, H. J., \& Carpenter, D. R. (2007). Qualitative research in nursing: Advancing the humanistic imperative (4th ed.). Philadelphia, PA: Lippincott, Williams, and Wilkins.

Tidwell, T., Edwards, J., Snider, E., Lindsey, C., Reed, A., Scroggins, I., ... Brigance, J. (2011). A nursing pilot study on bedside reporting to promote best practice and patient/family-centered care. Journal of Neuroscience Nursing, 43(4), E1-E5. https://doi.org/10.1097/JNN.0b013e3182212a1d

Timonen, L., \& Sihvonen, M. (2000). Patient participation in bedside reporting on surgical wards. The Journal of Clinical Nursing, 9, 542-548. https://doi.org/10.1046/j.1365-2702.200.00400.x

Wakefield, D. S., Ragan, R., Brandt, J., \& Tregnago, M. (2012). Making the transition to nursing bedside shift reports. The Joint Commission Journal on Quality and Patient Safety, 38(6), 243-253. https://doi.org/10.1016/S1553-7250(12)38031-8

Williams, C. (2018). A comparison of the risks and benefits of nursing bedside shift report vs. traditional shift report: A systematic review of the literature. International Journal of Studies in Nursing, 3(2), 40-43. https://doi.org/10.20849/ijsn.v3i2.382

\section{Copyrights}

Copyright for this article is retained by the author(s), with first publication rights granted to the journal.

This is an open-access article distributed under the terms and conditions of the Creative Commons Attribution license (http://creativecommons.org/licenses/by/4.0/). 